Acta Technologica Agriculturae 1

Nitra, Slovaca Universitas Agriculturae Nitriae, 2020, pp. 1-6

\title{
DETERMINING TRAFFICKED AREAS USING SOIL ELECTRICAL CONDUCTIVITY - A PILOT STUDY
}

\author{
Jana GALAMBOŠOVÁ ${ }^{1 *}$, Miroslav MACÁK' ${ }^{1}$, Vladimír RATAJ', Marek BARÁT' ${ }^{1}$, Paula MISIEWICZ² \\ ${ }^{1}$ Slovak University of Agriculture in Nitra, Slovak Republic \\ ${ }^{2}$ Harper Adams University, United Kingdom
}

\begin{abstract}
Increase in machinery size and its random traffic at fields cause soil compaction resulting in damage of soil structure and degradation of soil functions. Nowadays, rapid methods to detect soil compaction at fields are of high interest, especially proximal sensing methods such as electrical conductivity measurements. The aim of this work was to investigate whether electromagnetic induction (EMI) could be used to determine trafficked areas in silty clay soil. Results of randomized block experiment showed a high significant difference $(p<0.01)$ in EMI data measured between compacted and non-compacted areas. EMI readings from compacted areas were, on average, 11\% (shallow range) and 9\% (deep range) higher than non-compacted areas, respectively. This difference was determined in both shallow and deep measuring ranges, indicating that the difference in soil compaction was detected in both topsoil and subsoil. Furthermore, the data was found to have a significant spatial variability, suggesting that, in order to detect the increase in EMI (which shows the increase in soil compaction), data within close surrounding area should be included in the analyses. Correlation coefficient of EMI and penetration resistance (average moisture content $32.5 \%$ and $30.8 \%$ for topsoil and subsoil) was found to be 0.66 .
\end{abstract}

Keywords: EMI; CTF; proximal sensing; soil compaction

Soil compaction caused by vehicular traffic adversely affects the key soil functions and ecosystem services that soils provide (Keller et al., 2019). It has been shown that an increase in stress levels with higher bulk density and mechanical penetration resistance, and a decrease in soil hydraulic conductivity resulted in decreased root elongation rates and consequently prolonged the time required for roots to reach a certain soil depth. Soil compaction caused by machinery traffic needs to be: (a) either removed by costly subsoiling; or (b) avoided by implementation of technologies, such as wide span gantry technologies (Chamen, 2015; Bulgakov et al., 2018). Recently, controlled traffic farming (CTF) and its modifications show potential benefits worldwide (Godwin et al., 2015; Chamen, 2015; Gutu et al., 2015; Galambošová et al., 2017; Latsch and Anken, 2019; Antille et al., 2019; Masola et al., 2020). In order to conduct the aforementioned management steps, areas which were exposed to traffic should be spatially targeted. As soil compaction is defined as a change in the soil density, the most exact estimate can be obtained by measuring the soil density (Rataj et al., 2014). However, for practical reasons, traditional methods that rely on undisturbed soil samples are progressively being replaced by methods of proximal sensing. Proximal sensing comprises rapid methods, which enable measuring soil properties and producing soil maps with high resolution (Gebbers, 2019). Gebbers (2019) concluded that penetrometers and draft force sensors can be used for this purpose as direct methods. In terms of indirect methods, measuring the electrical conductivity of soil (ECa) has been employed in soil mapping recently. This is measured by two methods, galvanic couple electric resistivity (GCER) and electromagnetic induction (EMI). Heil and Schmidhalter (2017) reviewed the applications of ECa and concluded that not many studies have been conducted on determining the soil compaction using ECa. However, several studies (Krajčo, 2007; Alaoui and Diserens, 2018; Romero-Ruiz et al., 2019) show the potential of soil compaction targeting at field. So far, the most complex study was published by Krajčo (2007), who compared the Conductometer (GCEM) and the EMI measurement with favourable results for the former. On the basis of presented data, this latter study claims that the EMI was less sensitive in terms of distinguishing the compacted areas above $0.3 \mathrm{~m}$

Based on this, it is clear that there is still a lack of evidence in terms of direct assessment of this methods for targeting field trafficked/compacted areas. On the contrary, there is a need to examine these problems as current trends in precision agriculture are aimed at using soil proximal sensing, e.g. use of Topsoil Mapper (Geoprospectors $\mathrm{GmbH}$, Austria). Furthermore, there are attempts to use such data for online variable tillage treatment. Therefore, the aim of this work was to examine the ability of soil electrical conductivity to detect soil compaction caused by field traffic using electromagnetic induction measurements. 


\section{Material and methods}

As soil proximal sensing method, the apparent electrical conductivity (ECa) of the soil was measured by a non-contact method using the electromagnetic induction (EMI) with an EM38-MK2 device (Geonics Limited, Canada). When using EMI, the transmitter coil creates primary magnetic field in the soil, which reacts by establishing a secondary field. The superposition of these two fields results in a bulk magnetic field, which is measured using a receiver coil (Gebbers, 2019). The EM38-MK2 device was used in a horizontal mode; this means that the depth range of measurement was $0-0.38 \mathrm{~m}$ and $0-0.75 \mathrm{~m}$ for shallow and deep measurements, respectively.

\section{Experimental site}

Experiment was conducted at a research area of the Slovak University of Agriculture in Nitra (48 $18^{\circ} 07.4^{\prime \prime} \mathrm{N}$, $\left.18^{\circ} 05^{\prime} 52.8^{\prime \prime} \mathrm{E}\right)$. Soil texture analyses showed uniform soil texture across the site with a silty clay soil. The representation of the different fractions is provided in Table 1. Soil moisture content (MC) was measured in two depths $(0.10-0.15 \mathrm{~m}$ and 0.25-0.3 m) at each of the locations using disturbed samples (sampled with a soil auger) that were analysed using the gravimetric method (Reynolds, 1970). Measurement of EMI was conducted (a) before trafficking the experiment (on $29^{\text {th }}$ April 2019) and then (b) after trafficking to document the differences in compaction levels (on $30^{\text {th }}$ April 2019).

\section{Experimental layout}

The experiment was a randomised block design with three blocks and four plots each block (two trafficked and two non-trafficked), as shown in Fig. 1. Soil compaction was produced by 'multi-trafficking' of the area with a John Deere 8230 tractor $(11,406 \mathrm{~kg}$, front tyres: $600 / 70 \mathrm{R} 30,0.25 \mathrm{MPa}$, rear: 650/85 R38, $0.25 \mathrm{MPa}$ ) wheel by wheel and, as a result of that, the site comprised two variants:

1. Trafficked areas - Compacted plots;

2. Non-trafficked areas - Non-compacted plots (Control).

To document the difference between the variants in soil compaction, penetration resistance was measured using a Penetrologger (model P1.52, Eijlkelkamp Soil \& Water, Giesbeek, The Netherlands) with ten insertions $(n=10)$ at each of the 12 plots following the ASABE standard no EP 541 (ASABE, 1999).

\section{Software and statistical methods}

Statistical analyses were undertaken using Statistica (StatSoft Inc., 2013). These involved descriptive statistics followed by an analysis of variance (ANOVA) and the least significant differences $(L S D)$ to compare the means using probability levels of $95 \%$ and $99 \%$.
Direction of measurements across the plots

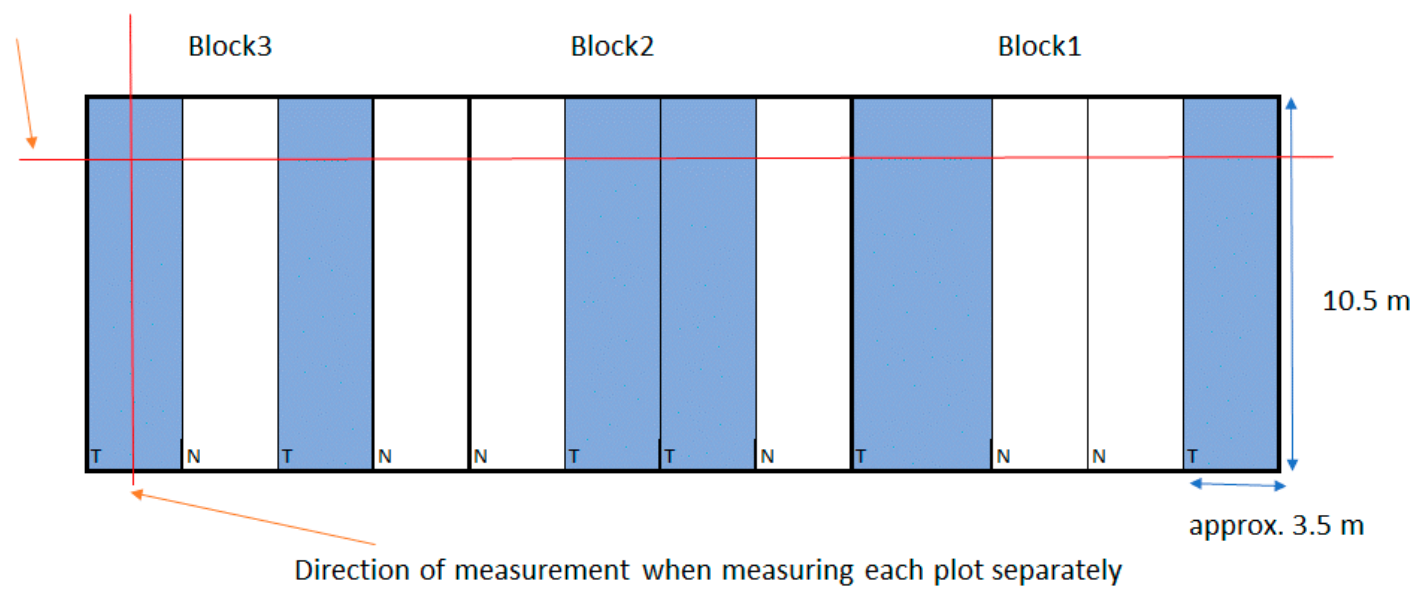

Fig. 1 Layout of the randomised block design experiment for soil electrical conductivity assessment

Table 1 Representation of different soil texture fractions at the experimental location

\begin{tabular}{|l||c|c|c|c|c|}
\hline \multirow{2}{*}{ Depth (cm) } & \multicolumn{5}{|c|}{ \% of whole particles } \\
\cline { 2 - 6 } & $\mathbf{7 0 . 2 5}$ & $\mathbf{0 . 2 5 - 0 . 0 5}$ & $\mathbf{0 . 0 5 - 0 . 0 1}$ & $\mathbf{0 . 0 1 - 0 . 0 0 1}$ & $<\mathbf{0 . 0 0 1}$ \\
\hline $\mathbf{0 - 3 0}$ & 1.75 & 4.35 & 14.85 & 38.72 & 40.31 \\
\hline $\mathbf{3 0 - 6 0}$ & 2.71 & 1.05 & 14.26 & 36.08 & 45.88 \\
\hline
\end{tabular}


The tests were conducted as one-factor analyses, which included the compaction level (of compacted and non-compacted areas). The same statistical approach was applied to investigate the effect of compaction, as well as spatial position (blocks), using ANOVA with two factors.

Spatial variability was displayed using ArcGIS (ESRI) and the spatial interpolation was performed by means of the Universal Kriging method for EMI values and IDW method for moisture content data. Correlation analysis was conducted as well.

\section{Results and discussion}

Before the wheel traffic was applied, the moisture content of the soil was $35.04 \%$ for the topsoil and $31.6 \%$ for the subsoil on average, with its spatial variability shown in Fig. 2. Further, the EMI was measured and the results of the scans before the trafficking are given in Fig. 3. These results indicate lower moisture content in subsoil in Block one and two and higher EMI values in deep horizon.

After trafficking was applied, soil strength was measured using a cone penetrometer (ASABE, 1999). The results shown in Fig. 4 (Left) were analysed using the ANOVA and showed a significant difference in the entire soil profile $(p<0.01)$, with the greatest difference in the topsoil (depth up to $0.1 \mathrm{~m}$ ). The actual soil MC measured from the soil samples

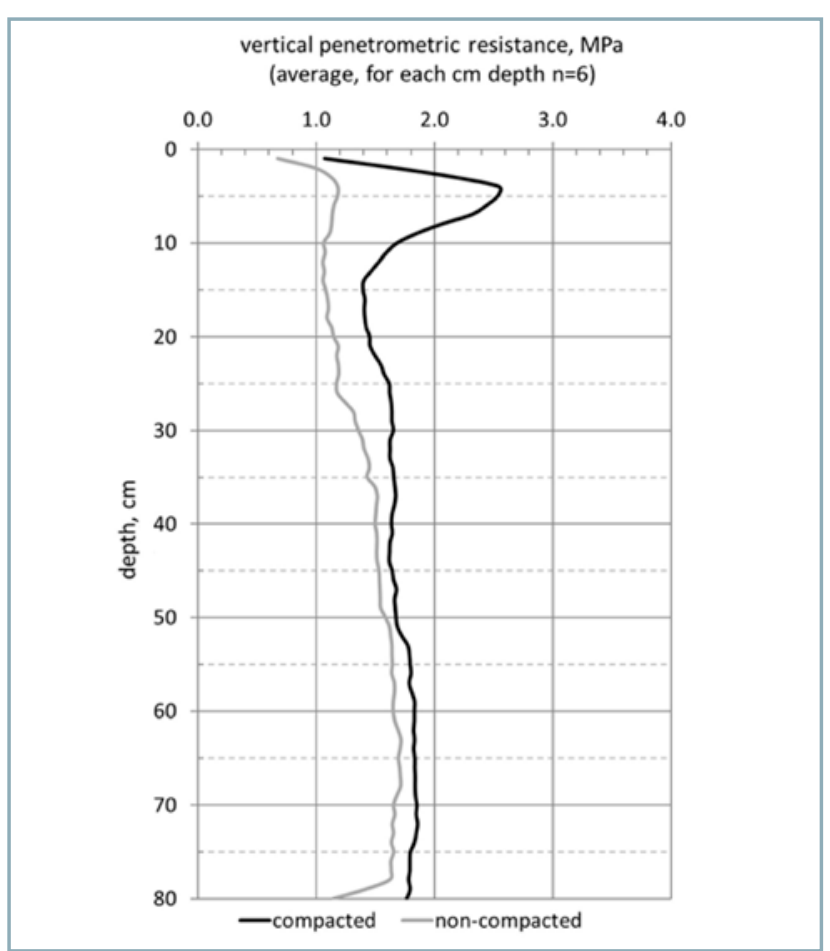

Fig. 4 Soil penetration resistance - average values for compacted and non-compacted plots (statistically significant difference at $p<0.01$ in whole depth)

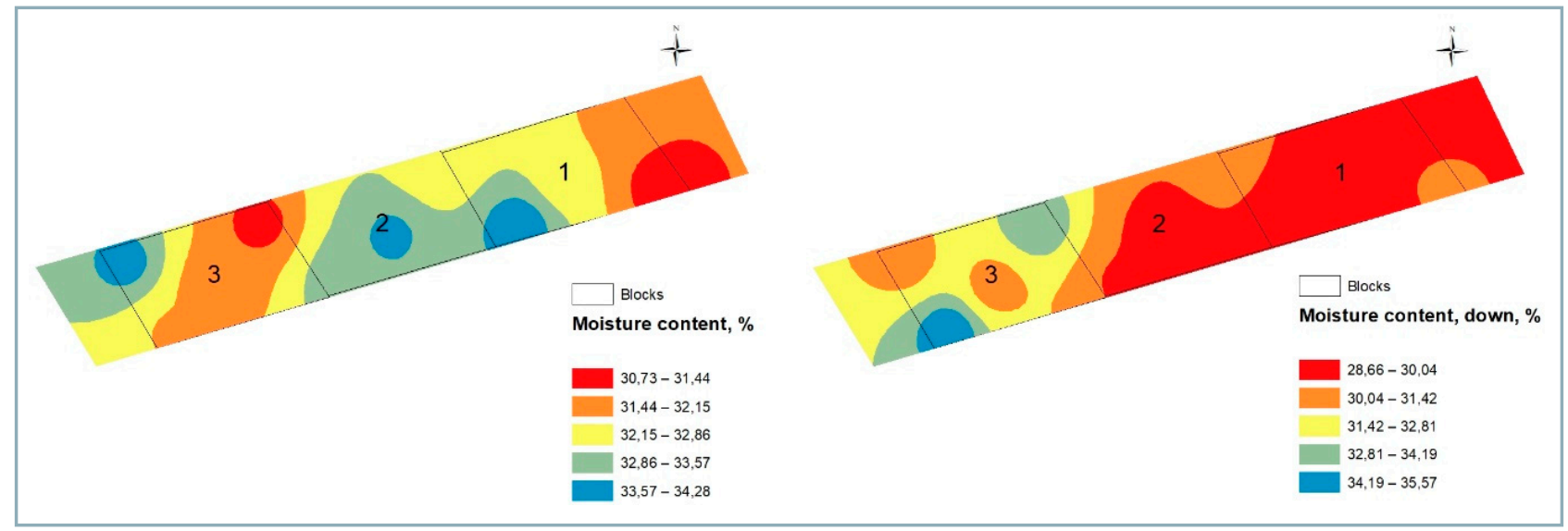

Fig. 2 Soil moisture content in the topsoil (Left) and subsoil (Right)

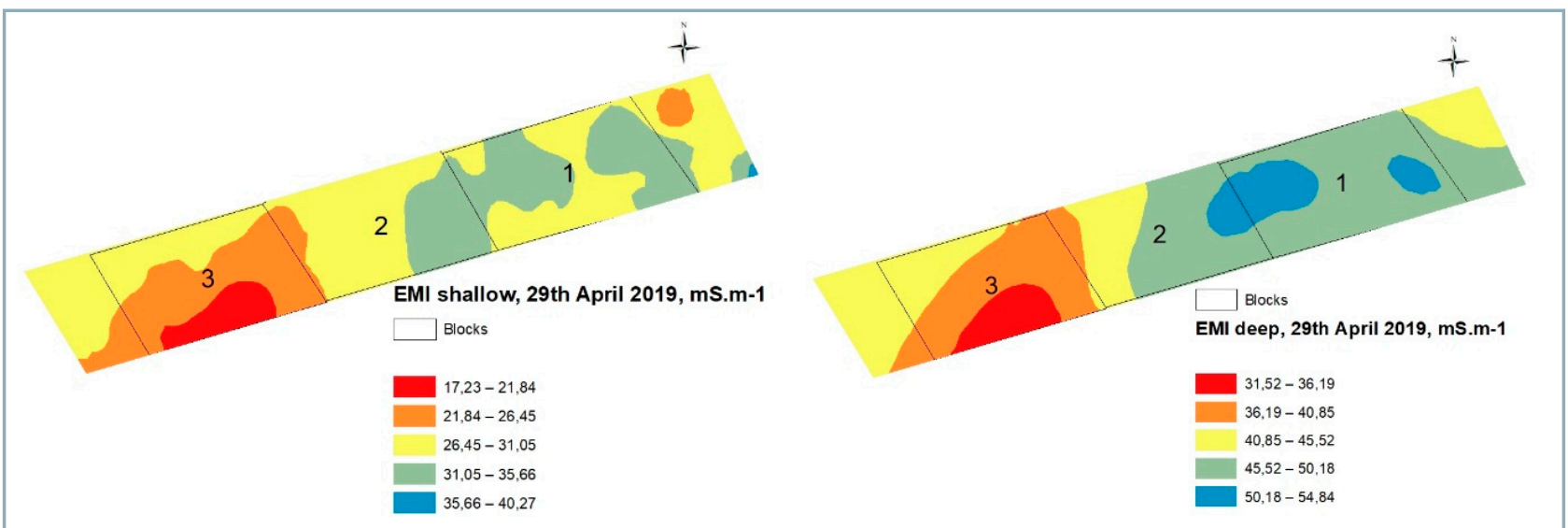

Fig. 3 Electromagnetic induction measured before the experiment in the shallow horizon (Left) and in the deep horizon (Right) 
Table 2 Average values of EMI determined in trafficked and non-trafficked areas measured in the shallow and deep horizons

\begin{tabular}{|l||c|c|}
\hline \multirow{2}{*}{ Depth horizon of EMI measurement } & \multicolumn{2}{|c|}{ EMI $\left(\mathbf{m S} \cdot \mathbf{m}^{-1}\right)$ (mean \pm SD) } \\
\cline { 2 - 3 } & trafficked areas & non-trafficked areas \\
\hline Shallow $\mathbf{( 0 - 0 . 3 8 ~} \mathbf{~})$ & $47.72 \pm 5.08^{\mathrm{a}}$ & $42.88 \pm 4.3^{\mathrm{b}}$ \\
\hline Deep $\mathbf{( 0 - 0 . 7 5} \mathbf{~ m})$ & $45.10 \pm 6.76^{\mathrm{a}}$ & $41.2 \pm 5.78^{\mathrm{b}}$ \\
\hline
\end{tabular}

$\mathrm{a}, \mathrm{b}$ - significantly different at $p<0.01$ when comparing the trafficked and non-trafficked areas at selected depths

analysed by gravimetric method was on average $30.8 \%$ for the topsoil and $32.5 \%$ for the subsoil.

The experimental site was observed using EM38-MK2 in two directions, as indicated in Fig. 1 (red lines). The device was handheld at an approximate distance of 100 $\mathrm{mm}$ above the ground. The results of a one-way ANOVA, in which all the three blocks were included, showed a highly significant difference in the EMI data at $p<0.01$; results are given in Table 2. The compacted areas were found to be characterised with higher mean values of EMI. Furthermore, the values for the shallow horizon were higher than with the results obtained in the deep horizon for both compacted and non-compacted variants.

Subsequently, the EMI was measured across the plots to simulate the movement of a machine on the field across compacted zones. The results are shown in Fig. 5 and the spatial variability of data is shown in Fig. 6 . The data were interpolated using the Universal Kriging function. As it is clear from Fig. 5, the general trend is that the values decrease from the east to the west direction. The differences between Block three and the rest of the experimental site in values of EMI were present before and after trafficking. Therefore, blocks were used as an indicator of spatial location. The twofactorial ANOVA was applied to data to observe the effect of both block (spatial location) and field traffic and the results are shown in Fig. 7.

The EMI results were found to be highly significantly different $(p<0.01)$ for the compacted and non-compacted areas in all the three blocks. This is valid for both the shallow and deep depth ranges - topsoil and subsoil, respectively. These findings bring a novel knowledge, since Krajčo (2007) did not find any significant difference between compacted and non-compacted areas in the topsoil in a randomized block design also using the EM38-MK2 device.

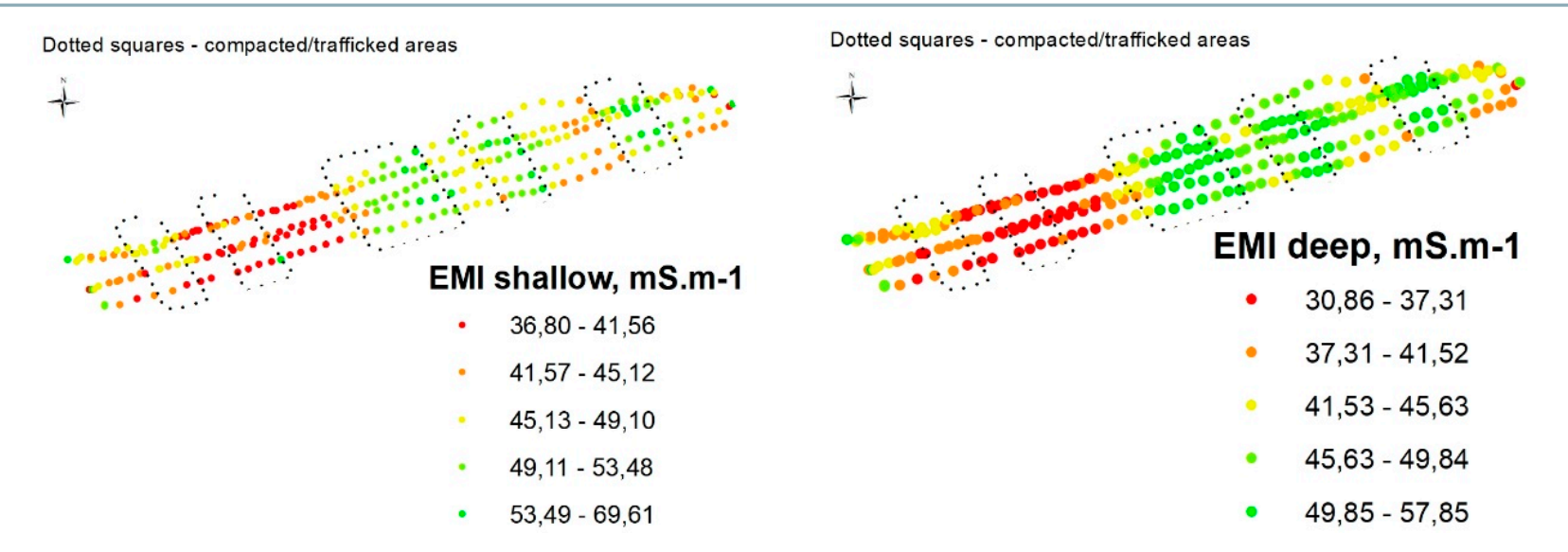

Fig. 5 EMI data $\left(\mathrm{mS} \cdot \mathrm{m}^{-1}\right)$ across the compacted and non-compacted areas at the shallow (Left) and deep depth range (Right)

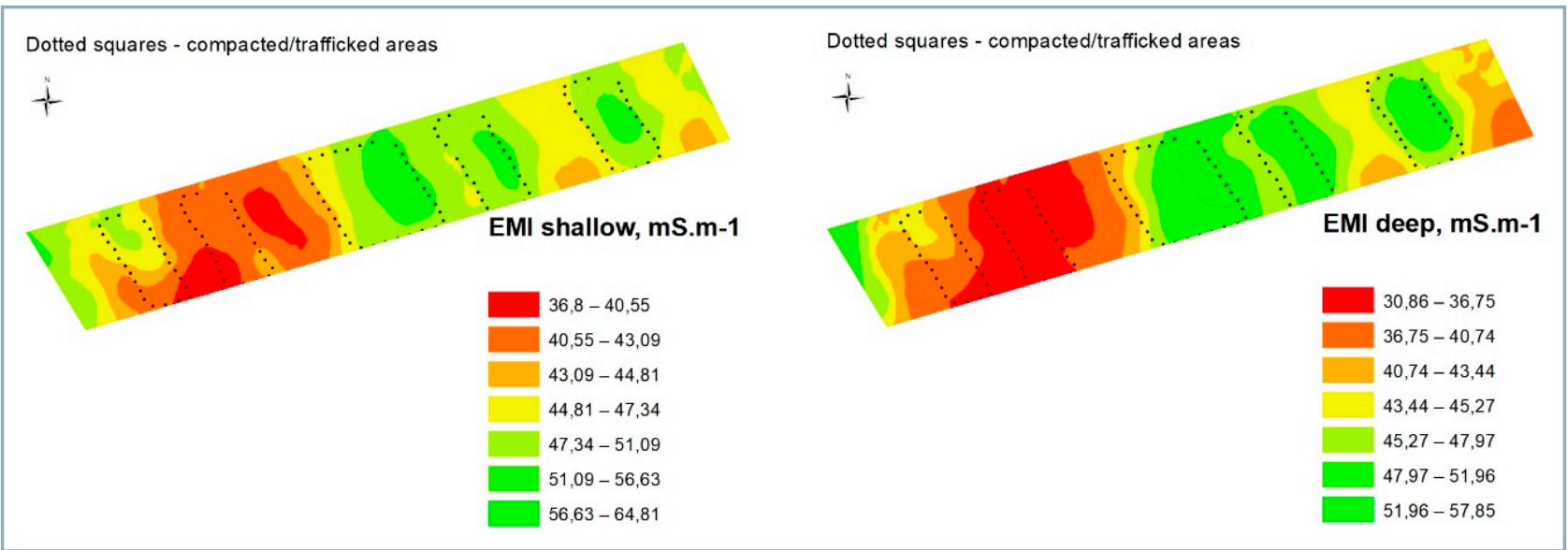

Fig. 6 Spatial variability of EMI for the compacted and non-compacted areas in the shallow (Left) and deep (Right) depth ranges 


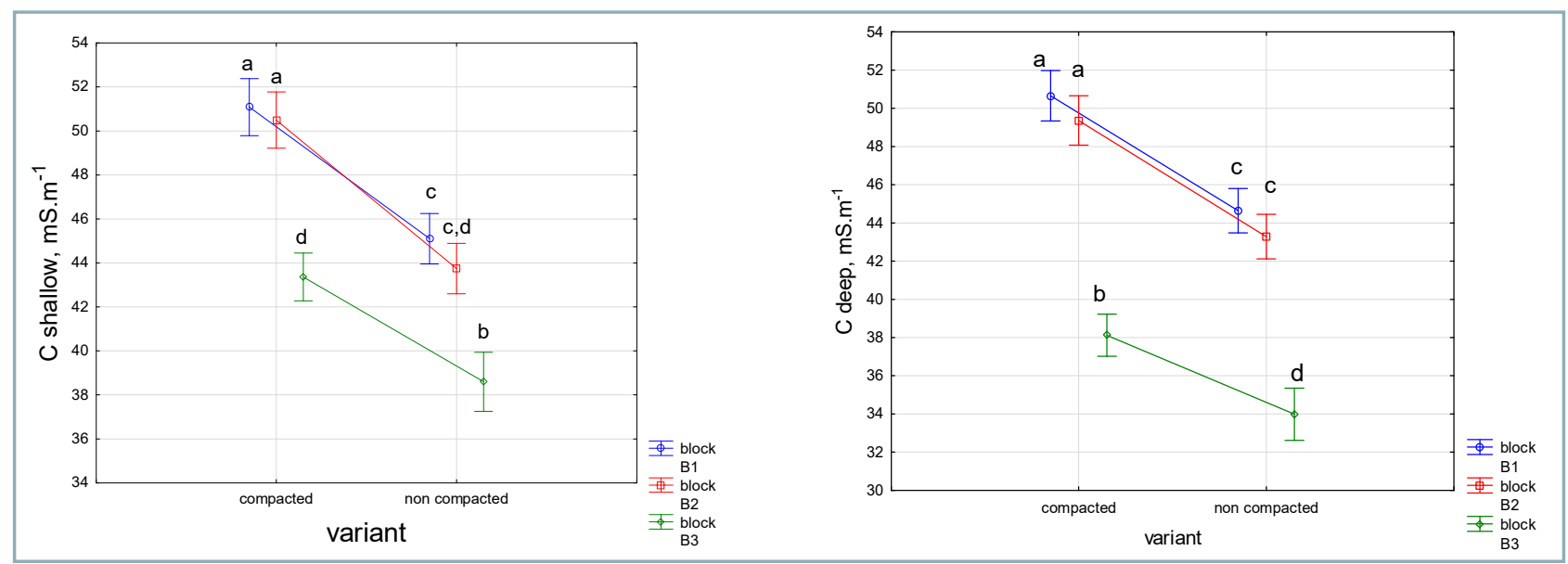

Fig. 7 Mean EMI values for the shallow (Left) and deep (Right) depth ranges for compacted and non-compacted plots/areas in three blocks ( $a, b, c$, d letters indicate the statistically different groups based on the LSD analyses)

For both depth ranges measured (shallow and deep), Block 3 was found to have significantly lower EMI values compared to Blocks 1 and 2, which were not significantly different from each other. This significant spatial variability within such a small distance $(42 \mathrm{~m})$, between Block 3 and the rest of the experimental site, can be explained by the variability in MC (Fig. 1 Right). From a practical point of view, it suggests that the values of EMI need to be compared with data on very close surroundings if the increase should be detected. Furthermore, incorporating spatially dense data on moisture content would be beneficial in terms of data interpretation. This agrees with Heil and Schmidhalter (2017), who stressed that the interpretation and utility of ECa readings are highly location- and soil-specific; the soil properties contributing to ECa measurements must be clearly understood.

Further, the EMI data were correlated with the measured penetration resistance and a statistically significant correlation coefficient of EMI to penetration resistance was found to be equal to 0.69 at $p<0.01$ for the shallow measurement depth (depth range up to $0.38 \mathrm{~m}$ ). Similar findings were published by Al-Gaadi (2012) for sandy soils, where the correlation coefficient was 0.69 at $8 \%$ soil MC. Hoefer et al. (2010) found similar relationship of penetrometer resistance and ECa at depth $0.30-0.40 \mathrm{~m}$ in loess-derived homogenous soil.

There is a potential that these data could be used to predict soil compaction caused by vehicular traffic. Further increase in precision could come from combination of EMI data with crop yield and other proximal sensing methods.

\section{Conclusion}

The results of the pilot study on the silty clay soil showed a potential of the EMI method to detect the trafficked areas of the field. Overall, a highly significant difference $(p<0.01)$ in EMI values between compacted and noncompacted areas with an average increase by $11 \%$ for compacted areas of the shallow soil horizon and by $9 \%$ for compacted areas of the deep soil horizon was found. A significant spatial variability of the data within the $42 \mathrm{~m}$ distance, was found (Blocks 1 and 2 significantly differed from Block 3); however, within each block, significant differences in compacted and non-compacted plots were still identified.

On the basis of the results, it can be recommended that EMI method can be used to determine the compacted areas in silty clay soil; however, data related to close surrounding area should be taken into account in the analysis.

\section{Acknowledgments}

This article was prepared in the framework of a research project funded by the European Union entitled ITEPAg: Application of Information Technologies to Increase the Environmental and Economic Efficiency of Production AgroSystem (ITMS 26220220014, www.itepag.uniag.sk) and project Building the Research Centre AgroBioTech' (ITMS no. 26220220180).

Authors would like to thank to the management of the Botanical Garden of the Slovak University of Agriculture in Nitra for providing the experimental site.

\section{References}

ANTILLE, D. L. - PEETS, S. - GALAMBOŠOVÁ, J. - BOTTA, G. F. RATAJ, V. - MACÁK, M. - TULLBERG, J. N. - CHAMEN, W. C. T. WHITE, D. R. - MISIEWICZ, P. A. - HARGREAVES, P. R. - BIENVENIDO, J. F. - GODWIN, R. J. 2019. Review: Soil compaction and controlled traffic farming in arable and grass cropping systems. In Agronomy Research, vol. 17, no. 3, pp. 653-682.

ASABE EP542: 1999. Procedures for Using and Reporting Data Obtained with the Soil Cone Penetrometer.

ALAOUI, A. - DISERENS, E. 2018. Mapping soil compaction A review. In Current Opinion in Environmental Science \& Health, vol. 5, pp. 60-66.

AL-GAADI, K. A. 2012. Employing electromagnetic induction technique for the assessment of soil compaction. In American Journal of Agricultural and Biological Sciences, vol. 7, no. 4, pp. 425-434.

BULGAKOV, V. - KUVACHOV, V. - NOZDROVICKÝ, L. - FINDURA, P. SMOLINSKYI, S. - IHNATIEV, Y. 2018.The study of movement of the wide span tractor-based field machine unit with power method of its control. In Acta Technologica Agriculturae, vol. 21, no. 4, pp. 160-165. 
GALAMBOŠOVÁ, J. - MACÁK, M. - RATAJ, V. - ANTILLE, D. L. GODWIN, R. J. - CHAMEN, W. C. T. - ŽITNÁK, M. - VITÁZKOVÁ, B. DUDÁK, J. - CHLPÍK, J. 2017. Field evaluation of controlled traffic farming in Central Europe using commercially available machinery. In Transactions of the ASABE, vol. 60, no. 3, pp. 657-669.

GEBBERS, R. 2019. Proximal soil surveying and monitoring techniques. In STAFFORD, J. Precision Agriculture for Sustainability. UK : Burgleigh Dodds.

GODWIN, R. - MISIEWICZ, P. - WHITE, D. - SMITH, E. - CHAMEN, T. - GALAMBOŠOVÁ, J. - STOBART, R. 2015. Results from recent traffic systems research and the implications for future work. In Acta Technologica Agriculturae, vol. 18, no. 3, pp. 57-63.

GUTU, D. - HŮLA, J. - KROULÍK, M. 2015. Evaluation of soil physical properties in system with permanent traffic lanes practised in 10 ha field. In Acta Technologica Agriculturae, vol. 18, no. 3, pp. 92-96. HEIL, K. - SCHMIDHALTER, U. 2017. The application of EM38: Determination of soil parameters, selection of soil sampling points and use in agriculture and archaeology. In Sensors, vol. 17, no. 11 p. 2540.

HOEFER, G. - BACHMANN, J. - HARTGE, K. H. 2010. Can the EM38 Probe Detect Spatial Patterns of Subsoil Compaction? In VISCARRA ROSSEL, R.A. et al. (eds.). Proximal Soil Sensing, Progress in Soil Science 1, 265, C Springer Science+Business Media B.V.

CHAMEN, T. 2015. Controlled traffic farming - from worldwide research to adoption in Europe and its future prospects. In Acta Technologica Agriculturae, vol. 18, no. 3, pp. 64-73.
KELLER, T. - SANDINA, M. - COLOMBIA, T. - HORND, R. - ORE, D. 2019. Historical increase in agricultural machinery weights enhanced soil stress levels and adversely affected soil functioning. In Soil and Tillage Research, vol. 194, p. 104293.

KRAJČO, J. 2007. Detection of Soil Compaction Using Soil Electrical Conductivity. MSc. Thesis, Cranfield University, Cranfield, UK.

LATSCH, A. - ANKEN, T. 2019. Soil and crop responses to a "light" version of Controlled Traffic Farming in Switzerland. In Soil and Tillage Research, vol. 194, p. 104310.

MASOLA, M. J. - ALESSO, C. A. - CARRIZO, M. E. - BERHONGARAY, G. - BOTTA, G. F. - HORN, R. - IMHOFF, S. 2020. Advantages of the one-wheeled tramline for multiple machinery widths method on sunflower (Helianthus annus L.) and maize (Zea mays L.) responses in the Argentinean Flat Pampas. In Soil and Tillage Research, vol. 196, p. 104462

RATAJ, V. - GALAMBOŠOVÁ, J. - MACÁK, M. - NOZDROVICKÝ, L. 2014. Precision Agriculture - System, Machines, Experiences. Nitra : Profi Press. (In Slovak: Presné pol'nohospodárstvo - Systém, stroje, skúsenosti).

REYNOLDS, S. G. 1970. The gravimetric method of soil moisture determination: Part I. A study of equipment, and methodological problems. In Journal of Hydrology, vol. 11, no. 3, pp. 258-273.

ROMERO-LUIZ, A. - LINDE, N. - KELLER, N. - ORE, D. 2019. A review of geophysical methods for soil structure characterization. In Reviews of Geophysics, vol. 56, pp. 672-697. 